www.jmscr.igmpublication.org

Impact Factor 5.244

Index Copernicus Value: 83.27

ISSN (e)-2347-176x ISSN (p) 2455-0450

crossref DOI: _http://dx.doi.org/10.18535/jmscr/v4i9.28

Journal Of Medical Science And Clinical Research

IGM Publication

An Official Publication of IGM Publication

\title{
Colorectal Cancer: Knowledge and Risk Factors among Adults in a Suburban Nigerian Community
}

\section{Adeoti, ML ${ }^{1}$, Oguntola, $\mathrm{SA}^{1}$, Olugbenga-Bello, $\mathrm{AI}^{2}$, Oladimeji, $\mathrm{OJ}^{3}$, Jegede, $\mathrm{SO}^{3}$}

${ }^{1}$ Department of Surgery, Faculty of Clinical Sciences, College of Health Sciences, Ladoke Akintola

University of Technology, Osogbo, Osun State Nigeria.

${ }^{2}$ Department of Community Medicine, Faculty of Clinical Sciences, College of Health Sciences, Ladoke

Akintola University of Technology, Osogbo, Osun State Nigeria.

${ }^{3}$ Department of Community Medicine, Ladoke Akintola University of Technology (LAUTECH) Teaching

Hospital, Ogbomoso, Oyo State, Nigeria

Corresponding Author

Olugbenga-Bello A.I.

LAUTECH Teaching Hospital Ogbomoso, Oyo State, Nigeria

Email:nike_bello@yahoo.com,Phone:08033839282

\section{ABSTRACT}

Background: Colorectal cancer is one of the major health problems in the world. It used to be thought that it is a disease of people in developed countries, but recent studies has shown increasing incidence in developing countries. In Nigeria most patients present late in Duke stage 3 or 4 when curative resection is impossible.To achieve higher success, improvement of knowledge and awareness not only for early symptoms but also for early detection methods and screening tools should be an important part of this strategy.

Aim: To determine the knowledge of adults about the symptoms and screening methods for colorectal cancer as well as determine the prevalence of risk factors for colorectal cancer among adults in Ogbomoso North Local government Area.

Methodology:This study shall be a descriptive cross-sectional study with a sample size of 600 using a pretested semi strutured interview administered questionnaire. Statistical Package for social sciences(SPSS) Version 17 shall be used for analysis.

Conclusion: Colorectal cancer is a condition that could be fatal with late presentation and mostly when clinical features manifest, they do with complications. Routine screening should be a priority to prevent late presentations and its complications which this study is geared to explore.

Keywords: Colorectal carcinoma; Screening; Knowledge; Risk factors; Adults.

\section{INTRODUCTION}

Background information: Colon cancer is a malignant tumor that develops from the epithelial cells of the inner (mucosal) shell. The uncontrolled growth of cancer cells leads to a tumor mass filling the intestinal lumen and disruption of its terrain. It is important to note that this type of cancer is capable of germinating through all layers of the affected intestine, extending to nearby organs of the abdominal cavity, as well as metastasizing to nearby lymph nodes and other parts of the body. More often 
bowel cancer develops from the so-called precancerous diseases - polyps, but a timely diagnosis helps prevent the development of this disease. Cancer of the colon and rectum was considered to be rare in Africa three to four decades ago, this has been adduced to the starchy, high-fiber, spicy, peppery foodstuff low in animal protein which many West African nations consumer ${ }^{1}$ However with increasing change in eating culture and proliferation of fast food joints, this is no longer true. As was observed in a Nigerian study in Ilorin ${ }^{2}$, 36patients with rectal cancer were seen over 4 years, with 1:1 male to female ratio, $38.9 \%$ of this patient were below 40 years of age, a male:female ratio of 1:1.5 has also been observed,Ibrahim et alworking in Ilorin found the peak age of occurrence for males was between 51 and 60 years, while that of the females was between 41 and 50 years. The malignancy was found in the rectum in $60.2 \%$ of the cases, while the least affected site is the descending colon (1.2\%). They found the exophytic occluding masses in $82.2 \%$ of the cases, and the most common histological type is adenocarcinoma (77.2\%) with well-, moderately, and poorly differentiated forms constituting $52.3 \%, 32.8 \%$, and $14.9 \%$ respectively. $^{3}$

The common presenting signs are weight loss, anaemia, change in bowel habits, passage of bloody and/or mucoidstool . Some others present with intestinal obstruction. In the advanced stages of the disease, abdominal pain, bloating, nausea, vomiting and signs of acute intoxication are major features. Ileus is an urgent surgical condition that threatens the patient's life and requires immediate treatment; symptoms of metastatic lesions of the internal organs might also be observed. A timely diagnosis of colon cancer significantly improves the prognosis of a full recovery, therefore when the first symptoms of suspected malignancy arise, medical assistance should be sought for.

Among several risk factors that may increase a person's chance of developing colorectal polyps or colorectal cancer includelifestyle-related factors. The links between diet, obesity, exercise and colorectal cancer risk are some of the strongest for any type of cancer. A diet that is high in red meats (such as beef, pork, lamb, or liver) and processed meats (hot dogs and some luncheon meats) can increase colorectal cancer risk. Cooking meats at very high temperatures (frying, broiling, or grilling) creates chemicals that might increase cancer risk, but it is not clear how much this might contribute to an increase in colorectal cancer risk ${ }^{3}$. Diets high in vegetables, fruits, and whole grains have been linked with a decreased risk of colorectal cancer ${ }^{4}$, but fiber supplements do not seem to help ${ }^{4}$. Lack of physical activity,obesity, raises the risk of colon cancer in both men and women, but the link seems to be stronger in men.Long-term smokers are more likely than nonsmokers to develop and die from colorectal cancer ${ }^{5}$. Smoking is a well-known cause of lung cancer, but it is also linked to other cancers, like colorectal. Heavy alcohol use ${ }^{4}$ may tend to lead users having low levels of folic acid in the body. Other risk factors, includes age, younger adults can develop colorectal cancer, but the chances increase markedly after age $50^{5}$. About 9 out of 10 people diagnosed with colorectal cancer are at least 50 years old $^{5}$.Further, personal history of colorectal polyps or colorectal cancer, personal history of inflammatory bowel disease, which includes ulcerative colitis and Crohn's disease, family history of colorectal cancer or adenomatous polyps, inherited syndromes are all known risk factors for CRC. Estimated 5\% to $10 \%$ of people who develop colorectal cancer have inherited gene defects (mutations) that can cause family cancer syndromes and lead to them getting the disease ${ }^{6}$, these syndromes often lead to cancer that occurs at a younger age than is usual ${ }^{7}$, (they are also linked to other cancers besides colorectal cancer). Familial adenomatous polyposis (FAP), and Hereditary non-polyposis colon cancer (HNPCC) also known as Lynch syndrome which accounts for about $2 \%$ to $4 \%$ of all colorectal cancers are all implicated in the development of CRC. 
The primary preventive measures ofCRC is speculative and prevention is more on the premises of secondary prevention in the form of early diagnosis and treatment ${ }^{3}$. This include colonoscopicpolypectomy, which study have shown to have resulted in a lower than expected incidence of colorectal cancer ${ }^{8}$ and upto $50 \%$ with influence lasting 6 years in another study ${ }^{5}$. Flexible sigmoidoscopy screening has also been demonstrated to have reduced distal colorectal cancer by $50 \%$ in the $\mathrm{UK}^{2}$. Furthermore, biennial screening by FOB test has been shown to reduce CRC mortality in a study done in Denmark. ${ }^{4}$ CRC mortality, including deaths attributable to complications from CRC treatment, was significantly lower in the screening group than in controls (mortality ratio 0.82 [95\% CI $0.68-$ $0 \cdot 99]) \mathrm{p}=0 \cdot 03)$. The role Short-chain fatty acids (SCFAs: acetate, propionate, $n$-butyrate) arising in the large bowel during bacterial fermentation of dietary fiber and starch have been documented to inhibit the growth of colon cancer cell lines.(R6). In the same vein, Aspirin appears to be effective at reducing the incidence of colonic adenoma and colorectal cancer, especially if used in high doses for more than 10 years $^{7}$. However, the possible harms of such apractice require careful consideration. [

Colorectal cancer is one of the major health problems in the world. It used to be thought that it is a disease of people in developed countries, but recent studies has shown increasing incidence in developing countries22.23,24 This may be due to changing life styles of Africans who now prefer to eat European diets. Among the cancer types, colorectal cancer is the second widespread cancer among the males and the third among females in the world ${ }^{8}$. According to the 2008 data, there are 1.2 million new patients who are diagnosed with colorectal cancer and 608.700 deaths (Jemal et al., 2011).In Nigeria most patients present late in Duke stage 3 or 4 when curative resection is impossible. In our practice we have encountered patients as young as 18 years.
Much work and studies had been done in the areas breast cancer awareness, knowledge and attitude and it is progressively yielding results as many afflicted with cancer of breast now present early ${ }^{9}$. The same cannot be said about colorectal cancer which is afflicting both young and old and most of them present when the disease is at an advanced stage. Most of them admit to seeing some of the early symptoms which they ascribe to "jedi-jedi"a local diagnosis consisting of unrelated multiple symptoms like anal protrusion, constipation, anal pruritus, passage of mucoid/bloody stools, low back pain, loss/reduced lilido etc. For interventional awareness campaign, the base-line knowledge about colorectal cancer and prevention as well as prevalence of the risk factors among those at risk is desirable and this is the purpose of this study. Although considerable progress has been achieved in the diagnosis and treatment of colorectal cancer, but there are several questions that are still unanswered concerning the public knowledge of this disease.To achieve higher success, improvement of knowledge and awareness not only for early symptoms but also for early detection methods and screening tools should be an important part of this strategy.Generally, this study will seek to determine the knowledge of adult male and female about the symptoms and screening methods for $\mathrm{CRC}$ as well as determine the prevalence of risk factors for CRC among the respondents.

\section{MATERIALS AND METHODS}

Ogbomosois a city in Oyo State, southwestern Nigeria, on the highway. It was founded in the mid-17th century. The population was approximately 645,000 in 1991 , by March 2005, it was estimated at around 1,200,000. Ogbomoso comprises five LGAs, Ogbomoso south and North LGAs which are urban, Orire, Surlere and Ogooluwa LGAs which are rural. The study was carried out among adults in Ogbomoso metropolis, this comprises two LGAs, Ogbomoso South and North LGAs and these are part of the 33 LGAs in Oyo State. Oyo State is one of the 36 
states in Nigeria and it is located in the South Western Nigerian. Ogbomoso South is a Local Government Area in OyoState, Nigeria. Its headquarters are in the town of Arowomole. It has an area of $68 \mathrm{~km}^{2}$ and a population of 100,815 . The LGA was established in $1991 .{ }^{15}$ It is bounded in the North and South by Ogbomoso North and Ogo-Oluwa LGAs respectively while the Surulere and Oriire LGAs shared its Eastern and Western border respectively.Ogbomoso North also created in 1991, has a population of 225,561. The LGA is boundedin the West by Oriire Local Government, inthe East by Surulere Local Government, in the North by Surulere Local Government, and in the South by Ogbomoso South Local Government. Ogbomoso metropolis housed two tertiary and one secondary health care institution with several primary health care facilities including private hospitals.

Study Population: The study population consists of male and female adultsfrom the age of eighteen years in Ogbomoso metropolis

Study Design: This is a descriptive cross sectional study.

Sample size calculation: Sample size was calculated using Leslie Fishers formula for estimating minimum sample size in descriptive health studies for population more than 10,000

Sample size was calculated using reported Prevalence of knowledge of the clinical features and risk factors of colorectal cancer, $(75 \%)$

$\mathrm{n}=\mathrm{Z}^{2} \mathrm{pq} / \mathrm{d}^{2}$

Where $\mathrm{n}=$ Desired sample size

$\mathrm{Z}=$ Standard normal deviate, usually set at 1.96

$\mathrm{P}=$ proportion of target population from previous study $=0.75$

$\mathrm{q}=1-\mathrm{p}$,

$\mathrm{d}=$ degree of accuracy desired, usually set at 0.05

$\mathrm{n}=\underline{1.96^{2} \times 0.75 \times(1-0.75)}$

$0.05 \times 0.05$

$=288.12=289$ respondents

The minimum sample size was calculated for population $>10,000$ to be 289 . However, to allow for more representativeness, the study size was increased to 600 respondents
Inclusion/Exclusion criteria: The study population comprised consenting adults living in Ogbomoso metropolis, while those on a visit will be excluded.

Sampling Technique: The multi-stage sampling technique was used to select respondents, by first selecting 4 wards randomly out of ten from each of the LGA to make 8 wards in all. From each of the selected wards, systematic random sampling was used to select compounds, such that in a clockwise direction every third compound was selected starting from the first compound on the street. Then all the households in the selected compound were be sampled, and every consenting and eligible adults male and female in the household were recruited into the study. The purpose of the study was explained to each respondent and only those who which was administered by trained research assistants who are good in the local language using interviewer method. The questions were translated to the local language (for those that were not literate). The questionnaire was developed by a careful review of relevant literature and subjected to peer review. To ensure validity and reliability, independent persons translated the questionnaire to Yoruba and back to English.

The questionnaire comprised five sections as follows; Socio-demographic data, assessment of knowledge about colorectal cancer and prevention, social and family history, Nutritional History, medical and surgical history, anthropometric measurement. The waist hip ratio, weight and height of the patient were measured to determine the level of obesity. Waist hip ratio higher than 0.95 for males and 0.88 for females, weight $/$ height $^{2}$ higher than $24.9 \mathrm{~kg} / \mathrm{m}^{2}$ was considered overweight, higher than $30 \mathrm{~kg} / \mathrm{m}^{2}$ was considered obese and higher than $35 \mathrm{~kg} / \mathrm{m}^{2}$ considered as morbidly obese.. The random blood sugar was assessed, any value above $7.8 \mathrm{mmol} / 1$ was considered to be diabetic.

Data collection and management: Trained Community Health Extension Workers (CHEWs) were engaged in administering the questionnaires. 
Data extracted from the questionnaires were analyzed using Statistical Package for Social Sciences (SPSS) Version 17. Descriptive statistics was also applied to determine frequency of relevant variables in the study, while inferential statistical methods was used to test associations between variables, with $\mathrm{P}$ value set at $<0.05$.

\section{Outcome variables}

Computing knowledge score of colorectal carcinoma among the respondents

The question on awareness and knowledge about colorectal cancer were scored. For questions whose responses were either yes or no (or correct or incorrect) a correct answer was scored 1 and a wrong answer was scored 0. For questions with three responses, (Yes, No and I don't know), correct response was scored 2, don't know or no idea scored 1 while wrong response scored 0. Maximum score for knowledge computed was 44 and the mean score calculated were 29. The respondents who scored below mean were regarded as having good knowledge while those who scored up to or above mean were regarded as poor knowledge.

\section{Computing knowledge on risk factors}

The question on knowledge about risk factors on colorectal cancer were scored. For questions whose responses were either yes or no (or correct or incorrect) a correct answer was scored 1 and a wrong answer was scored 0. For questions with three responses, (Yes, No and I don't know), correct response was scored 2, don't know or no idea scored 1 while wrong response scored 0 .. Maximum score for knowledge computed was 29 and the mean score calculated were 19. The respondents who scored below mean were regarded as having good knowledge while those who scored up to or above mean were regarded as poor knowledge.

Computing Prevalence of risk factors of colorectal cancer

Compute risk factors of colo-recta cancer
Questions on risk factors of colorectal cancer were scored. For questions whose responses were either yes or no, those who had risk with Yes answer is scored 1 while those who had no is scored 0 . In terms of body mass index, those who are normal and underweight scored 0 , overweight 1 , obesity 2 and morbid obesity 3. Total score computed ranges from 4 and 20 with mean score of $15.3 \pm$ 4.6. Categorization was done using the mean score. Those with score below the mean are categorized as low risk while those with mean score and above classified as high risk.

Categorizing the respondent's attitude: For questions on attitude that had strongly agree, agree, indifferent, disagree and strongly disagree options, the response was scored 5,4,3,2,1 in that order for positive attitude and 1,2,3,4,5 for negative attitude. Total score computed was 33 and mean score is $23 \ldots$ Respondents who score above the mean score is said to have favourable attitude while those below the mean score is said to have unfavourable attitude

\section{Prevalence of uptake of screening methods among respondents}

The question on prevalence of uptake of screening methods of colorectal cancer were scored. For questions whose responses were either yes or no (or correct or incorrect) a correct answer was scored 1 and a wrong answer was scored $0 \ldots$ Maximum score for knowledge computed was 5.0 and the mean score calculated were 0.17 . The respondents who had no score were regarded as having poor while those who scored 1 and above were regarded as good

\section{Computing Prevalence of risk factors of colorectal cancer}

The question on Prevalence of risk factors of colorectal cancer were scored. For questions whose responses were either yes or no (or correct or incorrect) a correct answer was scored 1 and a wrong answer was scored 0. Maximum score for knowledge computed was 10 and the mean score 
calculated were 2.4. The respondents who scored below mean were regarded as having low risk while those who scored up to or above mean were regarded as high risk

Ethical consideration: Informed consent will be obtained from all participants, and they will be informed that participation is voluntary. All participants will be identified using only serial numbers, any information gathered will be kept confidential and will only be disclose only with their permission or as required by Law. The benefit of the research will be explained to the participant, and they shall have the freedom to withdraw without any penalty.

Study Limitation: A major study limitation was the fact that information about medical and surgical history of patients will be as volunteered by respondents and tests will not be carried out to objectively verify most of the information.

The Colorectal Cancer Risk Assessment Tool by the American National cancer institute is based on the first absolute risk model for colorectal cancer. The model was developed using data from two large U.S. population-based case-control studies of colon and rectal cancer, cancer incidence data from 13 NCI Surveillance, Epidemiology, and End Results (SEER) registries, and from national mortality rates. The Colorectal Cancer Risk Assessment Tool uses the respondent's answers about risk and preventive factors to calculate that person's absolute risk of colorectal cancer for a specific time period.

\section{RESULT}

In this study, 601respondents were interviewed and all of the respondents gave full responses to the questionnaire, giving a response rate of $100 \%$. Table 1 below shows the socio-demographic status of respondents. The calculated mean age is $42 \pm 1.26$, and modal age group is $29-43$ years. The study observed that, $329(54.7 \%) ; 255$ 42.4\%); 17 (2.8\%) were Christians, Muslims and traditional worshippers respectively. Majority,
$353(58.7 \%)$ were females. Ninety,(15\%) were single, while 439 (73\%) were married. Majority, $505(84 \%) ; 454(75.5 \%)$ were Yorubas and in monogamous family setting respectively. Secondary and tertiary educations were the highest levels of education attained by the respondents respectively.

This study observed that out of 601 respondents, $382(63.6 \%)$ claimed that colorectal carcinoma is rare, while $144(24 \%)$ were not sure. Less than half, $298(49.6 \%)$ knew it can occur below the age of 20 years. Five hundred and seven, $84.4 \%$ claimed bloody stool is caused by jedijedi, 271 (45.1\%) by cancer, $249(41.4 \%)$ can occur without any disease while $471(78.4 \%)$, claimed it is caused by dysentery. Two hundred and thirtyseven, (39.4\%), $506(84.2 \%)$, and 504 (83.9\%) said mucous tool is caused by cancer, jedijedi and dysentery respectively. In the same vein, 405 (67.4\%), 465 (77.4\%), 276 (45.9) claimed anal swelling or protrusion can be caused by pile, jedijedi and cancer respectively. Regarding constipation, $515(85.7 \%)$ knew constipation is the reduction in frequency of stool, $514(85.5 \%)$ agree prolonged constipation needs to be reported to doctor and $485(80.7 \%)$ said changing bowel habit is dangerous. (Table 2)

Three hundred and forty-five $(57.4 \%)$ of the respondents knew that the colon is part of the GIT, while $212(35.3 \%)$ said the colon is part urinary system respectively. Three hundred and fifty-four, $58.9 \%$ knew weight loss is common in advance cases of disease, while 152, $25.3 \%$ claimed weight loss with any other symptom is normal. Computed score on respondents knowledge of colorectal carcinoma showed that $340(57 \%)$ of the respondents had good knowledge while 261 (43\%) had poor knowledge. In the same vein, the study observed, that 308 $(51 \%)$ have adequate knowledge of risk factors for colorectal carcinoma while 293 (49\%) have inadequate knowledge.

Table 4 showed that, $164(27.4 \%)$ respondents were above 50 years old; $26(4.3 \%)$ have been diagnosed of inflammatory disease before; 59 
(9.8\%) had first degree relation with colorectal carcinoma; 25 (4.2\%) had history of colorectal carcinoma while 25 (4.2\%) respondents have been diagnosed of adenomatous polyp respectively. Three hundred and sixty (59.9\%), 337 (56.1\%) consume red processed meat and fatty diet respectively. While $310(48.1 \%)$ do not exercise weekly, 43 (7.2\%) smoke cigarette and 60 (10\%) take alcoholic drinks respectively. Computing the risk of CRC, it was found that 299 (49.8\%) respondents have high risk for developing colorectal carcinoma while 302 (50.2\%) have low risk for its development, Fig. 1.

Table 5 showed that $255(42.4 \%)$ respondents strongly agree that people with colorectal carcinoma can live long with early detection. Very few of the respondents, 25 (4.2\%), strongly agreed that sufferers do not need treatment. One hundred and fifty-nine, $(26.5 \%)$ respondents strongly agree to surgical operation as a modality of treatment. Seventy-one, (11.8\%) and $81(14.1 \%)$ strongly agree that colorectal carcinoma is treated only with spiritual means and only with herbal drugs respectively. Less than half, 218 (36.3\%), however strongly agree that colorectal carcinoma is treatable. Computing the respondent's attitude, it was found that $395(66 \%)$ respondents have favorable attitude, while 206 (34\%) have unfavorable attitude towards available treatment methods for colorectal carcinoma. The study observed a low uptake of screening measures among respondents as only $55(9 \%)$ had ever screened for colorectal cancer. Fig. 2

Table 6 shows that there is a significant difference between knowledge, attitude, ethnicity and religion on risk of developing colorectal cancer. Those with low knowledge are 6 times at risk compared to those with high knowledge. In addition, individuals with favorable attitude are 4 times less at risk of developing colorectal cancer than those with unfavorable attitude. Likewise non Yorubas are 6 times at risk of developing colorectal cancer than the Yorubas. Also, nonChristians are 6 times at risk of developing colorectal cancer than the Christians. There is a significant difference between knowledge of colorectal cancer and uptake of screening test. Using high knowledge as reference, individual with low knowledge are 3 times less likely to do screening for colorectal cancer compared to those with high knowledge. ( $\mathrm{P}<0.05$, OR: 0.28 , CI: 0.119 -0.673). (Table 7)

Table 1: Socio-demographic Characteristics of respondents

\begin{tabular}{|c|c|c|}
\hline Age of respondents & Frequency & Percent \\
\hline $14-28$ & 85 & 14.1 \\
\hline $29-43$ & 268 & 44.6 \\
\hline $44-58$ & 179 & 29.8 \\
\hline $59-73$ & 62 & 10.3 \\
\hline$>74$ years & 7 & 1.2 \\
\hline \multicolumn{3}{|c|}{ Religion of respondents } \\
\hline Christian & 329 & 54.7 \\
\hline Moslem & 255 & 42.4 \\
\hline Traditional & 17 & 2.8 \\
\hline \multicolumn{3}{|l|}{ Sex of respondents } \\
\hline Male & 248 & 41.3 \\
\hline Female & 353 & 58.7 \\
\hline \multicolumn{3}{|c|}{ Marital status of respondents } \\
\hline Single & 90 & 15 \\
\hline Married & 439 & 73 \\
\hline Widowed & 52 & 8.7 \\
\hline Divorced & 7 & 1.2 \\
\hline Separated & 13 & 2.2 \\
\hline \multicolumn{3}{|c|}{ Ethnic group of respondents } \\
\hline Yoruba & 505 & 84 \\
\hline Ibo & 70 & 11.6 \\
\hline Hausa & 26 & 4.3 \\
\hline \multicolumn{3}{|c|}{ Education of respondents } \\
\hline Primary & 84 & 14 \\
\hline Secondary & 223 & 37.1 \\
\hline Tertiary & 244 & 40.6 \\
\hline Post tertiary & 50 & 8.3 \\
\hline \multicolumn{3}{|l|}{ Occupational status of } \\
\hline Trading & 210 & 34.9 \\
\hline Artisan & 146 & 24.3 \\
\hline Professional & 148 & 24.6 \\
\hline Others & 97 & 16.1 \\
\hline \multicolumn{3}{|c|}{ Family setting of respondents } \\
\hline Monogamous & 454 & 75.5 \\
\hline Polygamous & 147 & 24.5 \\
\hline
\end{tabular}


Table 2: Respondents Knowledge about Colorectal cancer $(n=601)$

\begin{tabular}{|c|c|c|c|c|c|c|}
\hline Variable & $\begin{array}{l}\text { Yes } \\
\text { Freq }\end{array}$ & & $\begin{array}{l}\text { No } \\
\text { Freq }\end{array}$ & & $\begin{array}{l}\text { Don’t } \\
\text { know }\end{array}$ & $\%$ \\
\hline Colon cancer is rare. & 382 & (63.6) & 75 & (12.5) & 144 & 24 \\
\hline colon-rectalCancer of the colon can occur in people less than 20 yrs. & 298 & $(49.6)$ & 155 & $(25.8)$ & 148 & $(24.6)$ \\
\hline Presence of blood in the stool can be due to Jedijedi & 507 & $(84.4)$ & 39 & $(6.5)$ & 55 & $(9.2)$ \\
\hline Cancer & 271 & $(45.1)$ & 186 & $(30.9)$ & 144 & (24) \\
\hline Without any disease & 249 & $(41.4)$ & 105 & $(41.1)$ & 105 & $(17.5)$ \\
\hline Dysentary & 471 & $(78.4)$ & 70 & (11.6) & 60 & (10) \\
\hline Presence of Mucus in stool is normal & 43 & $(7.2)$ & 500 & $(83.2)$ & 58 & $(9.7)$ \\
\hline can occur with cancer & 237 & $(39.4)$ & 178 & (29.6) & 186 & $(30.9)$ \\
\hline Can be due to jedi-jedi. & 506 & $(84.2)$ & 48 & (8) & 47 & $(7.8)$ \\
\hline Can occur with dysentery & 504 & (83.9) & 40 & (6.7) & 57 & $(9.5)$ \\
\hline Swelling or protrusion from the anus Can be due to pile. & 405 & $(67.4)$ & 89 & $(14.8)$ & 107 & $(17.8)$ \\
\hline Jedi- jedi is a common cause & 465 & $(77.4)$ & 87 & $(14.5)$ & 49 & $(8.2)$ \\
\hline can arise from cancer & 276 & $(45.9)$ & 143 & $(23.8)$ & 182 & $(30.3)$ \\
\hline $\begin{array}{l}\text { Constipation can be defined as reduction in the number of times you } \\
\text { stool overtime. }\end{array}$ & 515 & $(85.7)$ & 49 & $(8.2)$ & 37 & $(6.2)$ \\
\hline Constipation is normal in the absence of vomiting & 152 & $(25.3)$ & 382 & $(63.6)$ & 67 & $(11.1)$ \\
\hline Prolonged constipation needs to be reported to doctor & 514 & $(85.5)$ & 38 & $(6.3)$ & 49 & $(8.2)$ \\
\hline If constipation changes to diarrhea, could mean a dangerous sign & 485 & $(80.7)$ & 61 & $(10.1)$ & 55 & $(9.2)$ \\
\hline $\begin{array}{l}\text { constipation with lower backpain is usually due to ingestion of sweet } \\
\text { food and drinks }\end{array}$ & 418 & $(69.6)$ & 104 & $(17.3)$ & 79 & $(13.1)$ \\
\hline
\end{tabular}

Table 3: Respondents knowledge about the risk factors, symptoms and screening method for Colon-rectal cancer

\begin{tabular}{|l|ll|ll|ll}
\hline Variable & $\begin{array}{l}\text { Yes } \\
\text { Freq }\end{array}$ & $\begin{array}{l}\text { No } \\
\text { Freq }\end{array}$ & $\%$ & $\begin{array}{l}\text { Don’t } \\
\text { Know }\end{array}$ & $\%$ \\
\hline CRC can be inherited from ones parent & 170 & $(28.3)$ & 295 & $(49.1)$ & 136 & $(22.6)$ \\
\hline High intake of fatty diet can be a cause & 365 & $(60.7)$ & 130 & $(21.6)$ & 106 & $(17.6)$ \\
\hline $\begin{array}{l}\text { Previous operation on the intestine can } \\
\text { contribute to its occurrence. }\end{array}$ & 286 & $(47.6)$ & 226 & $(37.6)$ & 89 & $(14.8)$ \\
\hline $\begin{array}{l}\text { Intake of large amount of canned ( preserved ) } \\
\text { and smoked food is dangerous. }\end{array}$ & 399 & $(66.4)$ & 103 & $(17.1)$ & 99 & $(16.5)$ \\
\hline $\begin{array}{l}\text { Regular intake of low-fiber food e.g. } \\
\text { Indomine, rice, spaghetti is risky }\end{array}$ & 325 & $(54.1)$ & 130 & $(36.1)$ & 59 & $(9.8)$ \\
\hline Typical African diet is protective. & 355 & $(59.1)$ & 161 & $(26.8)$ & 85 & $(14.1)$ \\
\hline Cigarette smoking can predispose to CRC & 353 & $(58.7)$ & 111 & $(18.5)$ & 137 & $(22.8)$ \\
\hline Alcohol consumption can lead to CRC. & 376 & $(62.6)$ & 130 & $(21.6)$ & 95 & $(15.8)$ \\
\hline $\begin{array}{l}\text { Colon diseases of infective origin can lead to } \\
\text { CRC. }\end{array}$ & 348 & $(57.9)$ & 132 & $(22)$ & 121 & $(20.1)$ \\
\hline $\begin{array}{l}\text { Early detection can be obtained by stool } \\
\text { examination for blood. }\end{array}$ & 396 & $(65.9)$ & 96 & $(16)$ & 109 & $(18.1)$ \\
\hline ever heard about Colonoscopy & 281 & $(46.8)$ & 268 & $(44.6)$ & 52 & $(8.7)$ \\
\hline $\begin{array}{l}\text { Sigmoidoscopy/ colonoscopy is useful for } \\
\text { early detection. }\end{array}$ & 398 & $(66.2)$ & 49 & $(8.2)$ & 154 & $(25.6)$ \\
\hline $\begin{array}{l}\text { Doing colonoscopy for everyone above } \\
\text { 50years of age is cost effective. }\end{array}$ & 206 & $(34.3)$ & 217 & $(21.6)$ & 265 & $(44.1)$ \\
\hline
\end{tabular}


Table 4: Prevalence of risk factors of CRC among respondents

\begin{tabular}{|l|l|l|}
\hline Variable & Frequency & Percentage \\
\hline Risk factors above 50 years & 164 & 27.3 \\
\hline Diagnosed of inflammatory bowel disease & 26 & 4.3 \\
\hline First degree relation with colon recta cancer & 59 & 9.8 \\
\hline History of colorectal cancer & 25 & 4.2 \\
\hline Diagnosed of adenomatous polyp & 25 & 4.2 \\
\hline Intake of red processed meat & 360 & 59.9 \\
\hline intake of fatty food & 337 & 56.1 \\
\hline Do not exercise weekly & 310 & 48.1 \\
\hline smoke & 43 & 7.2 \\
\hline Take alcohol drink & 60 & 10 \\
\hline BMI categorization & \multicolumn{2}{|l}{} \\
\hline Less than 18.5 & 23 & 3.8 \\
\hline Between 18.5 and 24.9 & 319 & 53.1 \\
\hline Overweight (25-29.9) & 171 & 28.5 \\
\hline Obesity(30 - 34.9) & 57 & 9.5 \\
\hline Morbid obesity (>35) & 31 & $5.2 \%$ \\
\hline
\end{tabular}

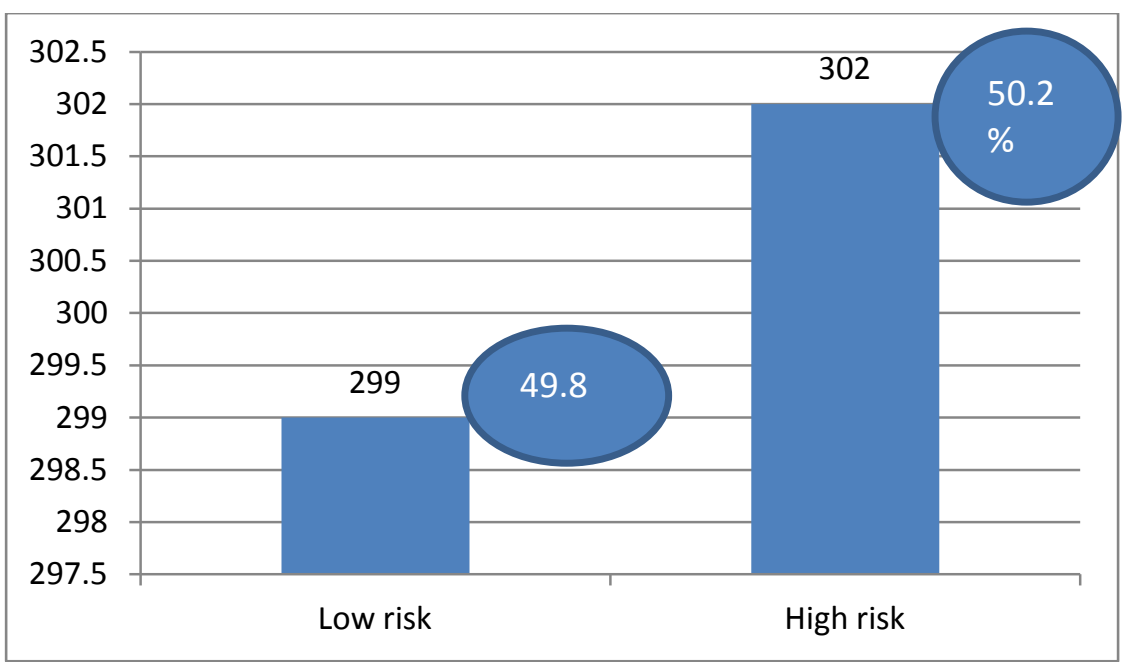

Fig. 1: Computed Risk level of respondents

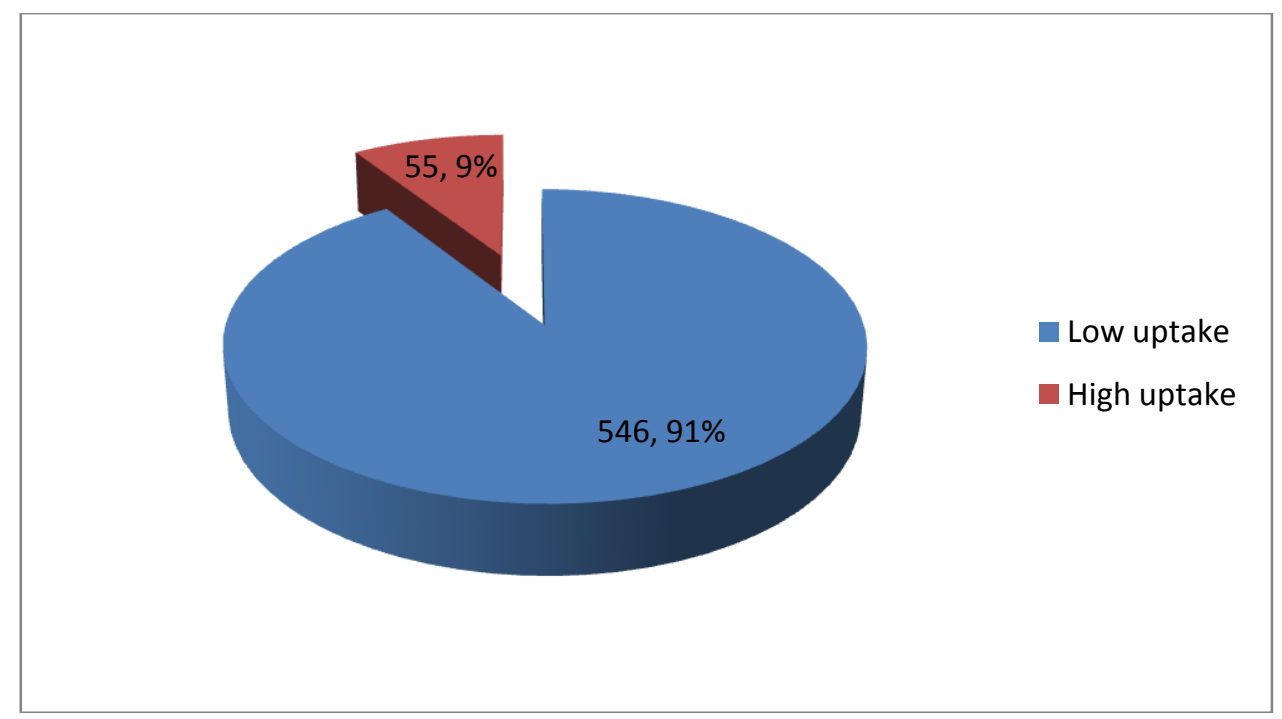

Fig. 2: Categorization based on overall score on uptake of screening procedure 
Table 5: Respondent's attitudes to readily available treatment methods $(\mathrm{n}=601)$

\begin{tabular}{|c|c|c|c|c|c|c|c|c|c|c|}
\hline & $\begin{array}{l}\text { Strongly } \\
\text { agree }\end{array}$ & $\%$ & Agree & $\%$ & Indiff & $\%$ & Disagree & $\%$ & $\begin{array}{l}\text { Strongly } \\
\text { disagree }\end{array}$ & $\%$ \\
\hline $\begin{array}{l}\text { Patient may live long with early } \\
\text { detection }\end{array}$ & 255 & (42.4) & 313 & $(52.1)$ & 13 & $(2.2)$ & 15 & (2.5) & 5 & $(0.8)$ \\
\hline $\begin{array}{l}\text { Kills the sufferer anyway, so no } \\
\text { need for treatment) }\end{array}$ & 25 & $(4.2)$ & 73 & (12.1) & 16 & $(2.7)$ & 301 & $(50.1)$ & 186 & (30.9) \\
\hline $\begin{array}{l}\text { Surgical operation is one of the } \\
\text { modality of treatment }\end{array}$ & 159 & $\begin{array}{l}(26.5) \\
\end{array}$ & 370 & $\begin{array}{l}(61.6) \\
\end{array}$ & 28 & $\begin{array}{l}(4.7) \\
\end{array}$ & 30 & (5) & 14 & (2.3) \\
\hline $\begin{array}{l}\text { Can be treated using spiritual } \\
\text { means }\end{array}$ & 71 & (11.8) & 173 & $(28.8)$ & 74 & (12.3) & 205 & (34.1) & 78 & (13) \\
\hline $\begin{array}{l}\text { Treatment with complimentary } \\
\text { drugse.g.Local herbs, GLND, } \\
\text { Tianshi, KEDI etc. is very } \\
\text { useful }\end{array}$ & 85 & (14.1) & 246 & $(40.9)$ & 74 & (12.3) & 151 & $(25.1)$ & 45 & $(7.5)$ \\
\hline It is curable. & 218 & (36.3) & 260 & $(43.3)$ & 61 & (10.1) & 50 & $(8.3)$ & 12 & (2) \\
\hline
\end{tabular}

Table 6: Predictors of High risk factors of colorectal cancer

\begin{tabular}{|c|c|c|c|c|c|}
\hline \multirow[b]{2}{*}{ Variable } & \multirow[b]{2}{*}{ Category of variable } & \multirow[b]{2}{*}{$\begin{array}{c}\text { Statistical } \\
\text { significance }\end{array}$} & \multirow[b]{2}{*}{$\begin{array}{l}\text { Odd } \\
\text { ratio }\end{array}$} & \multicolumn{2}{|c|}{$95 \%$ confidence interval } \\
\hline & & & & Upper level & $\begin{array}{c}\text { Lower } \\
\text { level }\end{array}$ \\
\hline Knowledge on Colorectal cancer & High knowledge (Reference) & 0 & 0.39 & 0.27 & 0.56 \\
\hline Attitude on colorectal cancer & $\begin{array}{c}\text { Favourable attitude } \\
\text { (Reference) }\end{array}$ & 0 & 4.6 & 3.2 & 6.6 \\
\hline Ethnicity & Yoruba (Reference) & 0 & 0.37 & 0.24 & 0.6 \\
\hline Religion & Christians (Reference) & 0 & 0.53 & 0.38 & 0.74 \\
\hline Age categories & Less than 50 years(Reference) & 0.114 & 1.35 & 0.93 & 1.95 \\
\hline
\end{tabular}

Table 7: Predictors of Good uptake of screening test for colorectal cancer

\begin{tabular}{|c|c|c|c|c|c|}
\hline \multirow[b]{2}{*}{ Variable } & \multirow[b]{2}{*}{ Category of variable } & \multirow[b]{2}{*}{ Statistical significance } & \multirow{2}{*}{$\begin{array}{l}\text { Odd } \\
\text { ratio }\end{array}$} & \multicolumn{2}{|c|}{$95 \%$ confidence interval } \\
\hline & & & & Upper level & Lower level \\
\hline $\begin{array}{ll}\text { Knowledge } & \text { on } \\
\text { Colorecta cancer }\end{array}$ & High knowledge (Reference) & & & & \\
\hline & Low knowledge & 0.002 & 0.28 & 0.119 & 0.673 \\
\hline $\begin{array}{l}\text { Attitude on colorectal } \\
\text { cancer }\end{array}$ & $\begin{array}{c}\text { Favourable attitude - } \\
\text { Reference }\end{array}$ & & & & \\
\hline & Unfavourable attitude & 0.965 & 1.013 & 0.565 & 1.815 \\
\hline Ethnicity & Yoruba (Reference) & & & & \\
\hline & Non-Yoruba's & 0.49 & 0.749 & 0.33 & 1.7 \\
\hline Religion & Christians (Reference) & & & & \\
\hline & Non-Christians & 0.164 & 0.667 & 0.375 & 1.184 \\
\hline Age categories & $\begin{array}{c}\text { Less than } 50 \\
\text { years(Reference) }\end{array}$ & & & & \\
\hline & Greater than 50 years & 0.572 & 0.825 & 0.423 & 1.61 \\
\hline
\end{tabular}

\begin{tabular}{|l|l|l|l|l|l|}
\hline & & & & \multicolumn{3}{|c|}{$95 \%$ confidence interval } \\
\cline { 5 - 7 } Variable & Category of variable & $\begin{array}{l}\text { Statistical } \\
\text { significance }\end{array}$ & Odd ratio & $\begin{array}{l}\text { Upper } \\
\text { level }\end{array}$ & Lower level \\
\hline Knowledge on Colorecta cancer & High knowledge (Reference) & 0.002 & 0.28 & 0.119 & 0.673 \\
\hline Attitude on colonrecta cancer & Favourable attitude (Reference) & 0.965 & 1.013 & 0.565 & 1.815 \\
\hline Ethnicity & Yoruba (Reference) & 0.49 & 0.749 & 0.33 & 1.7 \\
\hline Religion & Christians (Reference) & 0.164 & 0.667 & 0.375 & 1.184 \\
\hline Age categories & Less than 50 years(Reference) & 0.572 & 0.825 & 0.423 & 1.61 \\
\hline
\end{tabular}




\section{DISCUSSION}

This study assessed the knowledge of adult male and female about the symptoms and screening methods for CRC as well as determines the prevalence of risk factors for CRC among the respondents.

The mean age of correspondents is $42 \pm 1.26$, with majority falling within the age of 29 and 43 years. This is the group that probably has high risk factors for the development of colorectal cancer. This is contrary to a study carried out in USA by Heather M Brandt et al which showed a mean age of 60.3 (SD of 8.6). The male to female ratio is 1:1.4. This is also similar to the finding on prevalence of colorectal cancer by Ibrahim et al in Ilorin and Heather M Brandt et al in USA which gave male: female of $1: 1.5$ and $1: 1.7$ respectively. A good number of the study population is aware of colorectal cancer as about 6 out of 10 respondents have heard about colon cancer before however; about 4 out of 10 respondents have poor knowledge of what colorectal cancer is. This is also reflected in the answer given to the location of colon in the body where more than 3 out of 10 respondents taught the colon is part of the urinary system. Zaid Sayedalamin et al in a similar study done at Saudi Arabia among undergraduates revealed low awareness and knowledge level. This could be due to inadequate awareness campaign by health workers most especially those in the field of public health.

In this study, it was found that knowledge about the symptoms of colorectal cancer is low. A study done by Tin Tin Su et alat Malaysia showed that more than $70 \%$ of the interviewed subjects could not recall any sign unaided. This result is similar to what was gotten from a similar study done in the UK by Emily Power et al where there was low overall knowledge of the symptoms of colorectal cancer. However, the result among the index study population in Nigeria is better than what was got from a similar study done in Malaysia where only $5 \%$ could relate the symptoms to colorectal cancer without aid. In another study by Martins C.S Wong et al knowledge levels on colorectal cancer symptoms and risk factors were found to be relatively low. Worldwide, a substantial body of evidence pointed towards a low level of knowledge of colorectal cancer in many countries (Martins C.S Wong et al).

Overall the knowledge of the risk factors for development of colorectal cancer among the study population is low. More than half of the respondents have inadequate knowledge of the risk factors for development of colorectal cancer. This is similar to the findings got from undergraduates in Saudi Arabia where low knowledge was demonstrated. However, as expected, medical students in Saudi Arabia have better awareness of lifestyle, ageing and inflammatory bowel disease as risks for colorectal cancer than non-medical students. It is important that the healthcare professionals should take this opportunity to play an active role communicating the messages for cancer prevention through at the health care facilities and through the mass media. In a study carried out by Martins C.S Wong et al mean knowledge scores for symptoms and risk factors were 3.23 and 4.06 respectively. Also Martin C.S Wong et al discovered that male and smokers were more likely to have poorer knowledge but family history of colorectal cancer was associated with better knowledge. From the current study there is a significant association between knowledge and risk of developing colorectal carcinoma ( $\mathrm{p}$ value $<0.05$ and $\mathrm{CI}$ of 1.07-2.12.A huge percentage of respondents $(72 \%)$ have high risk in developing colon cancer. As regards screening methods, though close to half of the respondents claimed to have heard colonoscopy, the recommended age to start screening in average-risk population (50 years and above) was recognized by only 3 out of 10 respondents, which demonstrated a low level of knowledge compared to similar study by Papanikolaou, I.S., et al. done among Greek medical students with majority of their participants $(83 \%)$ able to identify the recommended age. 
As expected there is a significant association between age, educational status and occupation of respondents on knowledge of screening methods ( $\mathrm{p}$ value $<0.05$ ). This could be due to the fact that most respondents are educated and $40.6 \%$ of total respondents have at least tertiary level of education. In a similar study done by Tin Tin $\mathrm{Su}$ et al, respondents with higher education level and income have a higher level of awareness of colorectal cancer. Also Tin Tin $\mathrm{Su}$ et al study shows that socio-demographic characteristics and having cancer in family and friends play important role in level of awareness. The result of study by Heather M Brandt et al showed that gender, race, education, income, and urban or rural designation have significant association with knowledge score.

As regards prevalence of uptake of screening methods, 546 (91\%) respondents have low uptake for colorectal carcinoma screening methods while only 55 (9\%) have high uptake for colorectal carcinoma screening methods. The reason for this is not far-fetched as most participants in the survey have poor knowledge about colorectal carcinoma and its poor prognosis most especially at advanced stage. Several factors influence colorectal cancer screening uptake including socio-demographics, provider and health care system factors and psychosocial factors. A study done at Saudi Arabia by Eyad Demyati on perceived barriers of colorectal cancer screening shows that more than half $(56.2 \%)$ of the physicians are not practicing colorectal cancer screening for asymptomatic average-risk patients. Another study on uptake of colorectal screening done among Ontarians show only $26.3 \%$ of the study cohort had a fecal occult blood testing (FOBT) in the previous 2 years. Contrary to this finding, Heather M Brandt et al reported that $74 \%$ of respondents have had previous screening for colorectal cancer with majority indicating colonoscopy. Some studies found positive relationship between knowledge about colorectal cancer, risk perception and attitudes (perceived benefits and barriers against screening) and willingness to participate in a colorectal screening campaign. Health education is known to improve knowledge on colorectal carcinoma and screening uptake.

In this study, more than $60 \%$ respondents have favourable attitude towards available treatment methods for colorectal carcinoma. This study also shows no significant association between knowledge and attitude to readily available treatment methods ( $\mathrm{p}$ value $>0.05$ and $\mathrm{CI}$ of 0.8 1.6. However, similar study in the UK showed a total of $14 \%$ of the study population had a negative attitude towards CRC screening. Men, older people, and those with South-Asian ethnic backgrounds were more likely to have negative attitudes; whereas Black-Caribbean people, those with multiple symptoms, and those with abdominal pain, bleeding, and tiredness were more likely to have a compliant attitude ( $\mathrm{T}$ Taskila et al).

In Malaysia Tin Tin Su et al showed that the mean duration for seeking medical attention was 1.51 $( \pm 1.69)$ weeks. In other studies, majority of the population would seek medical attention within 2 weeks provided if they are aware with the signs and symptoms of CRC.

\section{REFERENCES}

1 Sidney J Winawer et al, Prevention of colorectal cancer by colonoscopicpolypec-tomy. The New England Journal of Med.

2 Wendy SA et al Flexible Sigmoidoscopy Trial Investigators. Once-only flexible sigmoidoscopy screening in prevention of colorectal cancer: a multicenter randomised controlled trial. The Lancetvol 376 issue 9726, 814t May 2014 pages 1624-1633. doi:10.1016/S0140-736(10)60551-X

3. MatteoG et al Prevention of colorectal cancer. Diseases September 1987, Volume 30, Issue 9, pp 692-696

4. Ole $\mathrm{K}$ et al Randomised study of screening for colorectal cancer with faecal-occult-blood test. The Lancet 1996; 348(9040):14671471. doi:10.1016/S0140-6736(96)03430-7 
5. Astrid D. Muller, MD, MS; and AmnonSonnenberg, MD, MSc Prevention of Colorectal Cancer by Flexible Endoscopy and Polypectomy: A Case-Control Study of 32702 Veterans .Ann Intern Med. 1995;123 (12):904910. doi:10.7326/0003-4819-123-12-19951215000002

W Scheppach, H.P Bartram, F RichterRole of short-chain fatty acids in the prevention of colorectal cancer

8. . European Journal of cancer 1996; 31 (7-8): 1077-1080. doi:10.1016/0959-8049(95)00165-F

7. Catherine Dubé, MD, MSc; AlaaRostom, MD, MSc; Gabriela Lewin, MD; Alexander Tsertsvadze, MD, MSc; Nicholas Barrowman, $\mathrm{PhD}$; Catherine Code, MD; Margaret Sampson, MILS; and David Moher, PhD. The Use of Aspirin for Primary Prevention of Colorectal Cancer: A Systematic Review Prepared for the U.S. Preventive Services Task ForceAnn Intern Med. 2007;146(5): 365-375. doi:10.7326/00034819-146-5-200703060-00009

8. Edward DG et al. Vitamin D and prevention of colorectal cancer. The Journal of steroid biochemistry and molecular biology 2006; 77(12): 179-196. doi:10.1016/j.jsbmb.2005.06.018

9. Jack DH et al. Randomised controlled trial of faecal-occult-blood screening for colorectal cancer. The Lancet 1996; 348(9040):14721477. doi:10.1016/S0140-6736(96)03386-7

10. Tin Tinn Su, Jun Yan Goh et al. Level of colorectal awareness; a crossectional study among multi-ethnic rural population in Malaysia. Biomed Central. BMC Cancer 2013; 13:376. doi:10.1186/1471-2407-13-376

11. Martins C.S. Wong, Hoyee W. Hirai. Arthurk. The Knowledge Of Colorectal Cancer Symptoms And Risk Factors Among 10,078 Screening Participants: Are High Risk Individuals More Knowledgeable? http://journals.plos.org/plosone/a rticle?id=10.1371/journal.pone. 0060366

12. Bruce S Ling, Mark A Moskowitz et al. Attitudes Towards Colorectal Cancer Screening Tests A Sure of Patients and Physicians. Journal of General Internal Medicine.
2001 Dec; 16(12): 822-830. doi: 10.1111/j.15251497.2001.10337.x

13. Antonio Z.Gimeno Garcia, et al. Public Awareness of Colorectal Cancer Screening: Knowledge, Attitude and Interventions for Increasing Screening Uptake. http://dx.doi.org/10.1155/2014/425787

14. EyadDemyati Knowledge, Attitude and Practice and Perceived Barriers of Colorectal Cancer Screening among Family Physicians in National Guard Health Affairs, Riyadh, Saudi Arabia. International Journal of Family Medicine vol 2014(2014), Article ID 457354, 7 pages. http://dx.doi.org/10.1155/2014/457354

15. Paul Ritro, Ronald E Myers et al. BioMed Central BMC Public Health. GenderDifferences in attitudes impending colorectal screening. doi:10.1186/1471-2458-13-500

16. Joseph C Anderson, ZviAlpern et al. Prevalence and Risk of Colorectal Neoplasia in Consumers of Alcohol in a Screening Population. American Journal of Gastroenterology 100, 20492055 (September 2003) 1572-0241.2005. doi:10.1111/j.41832.x

17. ZhengShu, Cain Shanrong. Colorectal Cancer Epidemiology and Prevention Study in China. The Chinese-German Journal of Clinical Oncology June 2003, Volume 2, Issue 2, pp72-75

18. Helene Ouellette-Kuntz et al. Uptake of olrectal Cancer Screening Among Ontarians with Intellectual and Developmental Disabilities. http://journals.plos.org/plosone/articl e?id=10.1371/journal.pone. 0118023

19. Hellen I. Meissner, Nancy Breen et al. Patterns of Colorectal Cancer Screening Uptake among Men and Women in the United States of America.

20. Heather M Brandt et al. Relationship of Colorectal Cancer Awareness and Knowledge with Colorectal Cancer Screening. Colorectal Cancer. 2012; 1 (5): 383-396. doi: $10.2217 /$ crc. 12.45

21. ZaidSyedalamin et al Assessment Of The Knowledge And Awareness Of Colorectal Cancer Among Undergraduate Students In Saudi Arabia: 
A Survey Based Study. American Journal of Research Communication. http://www.usajournals.com/wpcontent/uploads/2016/03/Sayedalamin_Vol43.pdf 22. T Taskila, S Wilsonet al. Factors affecting attitudes toward colorectal cancer screening in the primary care population. British Journal of Cancer (2009) 101, 250-255. doi:10.1038/sj.bjc.6605130

23. Emily Power et al.Assessing awareness of colorectal cancer symptoms: Measure development and results from a population survey in the UK.DOI: $10.1186 / 1471-2407-11-366$. http://www.biomedcentral.com/1471-2407/11/366 24. Papanikolaou, I.S., et al., Awareness and attitudes of Greek medical students on colorectal cancer screening. World J GastrointestEndosc, 2012. 4(11): p. 513-7. 